\title{
A study on prescribing pattern and drug utilization among depressed patients in a tertiary care teaching hospital
}

\author{
Thangamariyappan C. ${ }^{1 *}$, Deepika Karnan ${ }^{1}$, Roshini G. ${ }^{1}$, Manna P. K. ${ }^{1}$, Asok Kumar ${ }^{2}$
}

${ }^{1}$ Department of Pharmacy, Annamalai University, Annamalai Nagar, Chidambaram, Tamil Nadu, India

${ }^{2}$ Department of Psychiatry, RMMCH, Annamalai Nagar, Chidambaram, Tamil Nadu, India

Received: 10 September 2021

Accepted: 04 October 2021

\section{*Correspondence:}

Dr. Thangamariyappan C.,

Email: harishaakash03@gmail.com

Copyright: (C) the author(s), publisher and licensee Medip Academy. This is an open-access article distributed under the terms of the Creative Commons Attribution Non-Commercial License, which permits unrestricted non-commercial use, distribution, and reproduction in any medium, provided the original work is properly cited.

\begin{abstract}
Background: Drug utilization is defined as the marketting, distribution, prescribing and use of drugs in society. Various factors like quality, quantity, and cost of drugs plays an important role in selection of drug therapy. Hence we wanted to observe that drug utilization and prescribing pattern of antidepressants.

Methods: A prospective observational study were conducted in a psychiatric department at RMMCH for a period of 6 months from November 2019 to April 2020. Sixty patients were enrolled and analysed to study the pattern and the world health organisation (WHO) prescribing indicators.

Results: From 60 prescriptions, the most widely prescribed antidepressant drug escitalopram 21 (42\%) as a combination drug citalinforte $30(50 \%)$, linotril $21(42 \%)$ lorazepam $12(20 \%)$, haloperidol $6(10 \%)$ and quitipin $3(5 \%)$. Most commonly, depression was seen in age group between 31-40 years and males were more to depression than females. Most drugs were prescribed under brand names (55\%) than generic drugs (45\%). Monotherapy was the preferred drug pattern for the mild depression followed by dual therapy and triple therapy for moderate and severe depression respectively. The number of drugs which were prescribed from the WHO and national list of essential medicine (NLEM) was haloperidol $(10 \%)$ and escitalopram $(85 \%)$ respectively.

Conclusions: Escitalopram was the commonly prescribed drug for depression followed by lorazepam, linotril and haloperidol. Monotherapy was most preferred, because of increased medication adherence, low ADRs, minimum cost and lesser drug interactions compared to other therapies.
\end{abstract}

Keywords: Drug utilization, Prescribing pattern, Escitalopram

\section{INTRODUCTION}

Depression is very much a real illness and can affect one's mood,energy,thoughts and behaviour. WHO factsheet reported that more than 264 million people were affected by depression worldwide. ${ }^{1}$ The depressive disorders are characterized by sadness, loss of interest or pleasure, feelings of guilt or low self worth, disturbed sleep or apetite, feelings of tiredness and poor concentrations. Deficiency of monoamine hypothesis (serotonin, noradrenaline), neuroendocrine abnormalities and genetics can lead to depression and many drugs have been discovered for the treatment of depressions like selective serotonin reuptake inhibitor and tricyclic antidepressants. ${ }^{2}$

Drug utilization study is defined by the WHO as marketting,distribution and use of drugs in society with special emphasis on resulting medical, social an economic consequences. ${ }^{3}$ The purpose of drug utilization pattern is determination of benefit-risk relationship, cost effectiveness and can ensure the appropraite use of dose, duration of therapy and outcomes of therapy with drugs. ${ }^{4}$ Without the knowledge of prescribing pattern it would be difficult to rationale the drugs and to conduct the drug 
utilization research. The prescribing pattern promotes appropraite use of monitored drugs, reduction of abuse and ensures medical care rationale. ${ }^{5}$

\section{Aims and objective}

The aim and objectives of the study were to study the prescribing pattern and drug utilization review on depressed patients.

\section{METHODS}

A prospective observational study ws conducted in a psychiatric unit of a tertiary care teaching hospital RMMCH from November 2019-April 2020. Ethical clearance was obtained from the institutional ethics committee (IEC) before starting the study. We used the following inclusion as well as exclusion criteria for the study.

\section{Inclusion criteria}

Patients who were treated for depression either as inpatient or outpatient, all patients who were diagnosed with depression and patients between 13-59 years of age were included in the study.

\section{Exclusion criteria}

Patients who were not willing to participate in the study, patients under special groups (pregnancy women and lactating mothers) and patients with other psychiatric disorders were excluded from the study.

The data collection form included information about patient's name, age, sex, generic name and brand name drugs, antidepressant drug prescribed, rationality of the drug prescription in accordance with the NLEM. Prescription of all patients was entered in a performed preforma and was analyzed using descriptive statistics.

\section{Statistcal analysis}

The data was collected and entered in Microsoft excel software 2007 and interpreted by descriptive statistics that was presented to analyse and express the report as counts and percentages in the form of tables, charts and graphs.

\section{RESULTS}

Sixty prescriptions were analyzed during the study period and patients were classified as mild, moderate and severe depressed based on HAM-D scoring (Hamilton depression rating scale). ${ }^{6}$ Patients were prescribed with antidepressants, benzodiazepenes, antipsychiotic and others. The most preferred antidepressant was escitalopram $21(42 \%)$, followed by combination drug citalinforte $30(50 \%)$ and linotril $21(42 \%)$ as shown in the Table 1.
Table 1: Frequency of drug prescribed.

\begin{tabular}{|lll|}
\hline Drugs & $\begin{array}{l}\text { Number of } \\
\text { prescriptions }\end{array}$ & $\begin{array}{l}\text { Percentage } \\
(\%)\end{array}$ \\
\hline Citalin forte & 30 & 50 \\
\hline Escitalopram & 21 & 42 \\
\hline Linotril & 21 & 42 \\
\hline Haloperidol & 6 & 12 \\
\hline Lorazepam & 12 & 20 \\
\hline Quitipin & 3 & 5 \\
\hline Librium & 3 & 5 \\
\hline Rexite bt & 9 & 15 \\
\hline Bct & 18 & 30 \\
\hline Others & 18 & 30 \\
\hline
\end{tabular}

Also, it was observed that patients belonging to the age group between 31-40 years were more prone for the occurence of the depressive disorder (Table 2).

Table 2: Age wise distribution of patients.

\begin{tabular}{|lll|}
\hline Age (Years) & $\begin{array}{l}\text { Number of } \\
\text { prescriptions }\end{array}$ & $\begin{array}{l}\text { Percentage } \\
(\%)\end{array}$ \\
\hline $\mathbf{2 0}$ & 3 & 5 \\
\hline $\mathbf{2 1 - 3 0}$ & 19 & 31.5 \\
\hline $\mathbf{3 1 - 4 0}$ & 31 & 52 \\
\hline $\mathbf{4 0}$ & 7 & 11.5 \\
\hline
\end{tabular}

Furthermore, it was observed that, the depression was observed greatly among males (33) patients compared to females (27) patients (Figure 1).

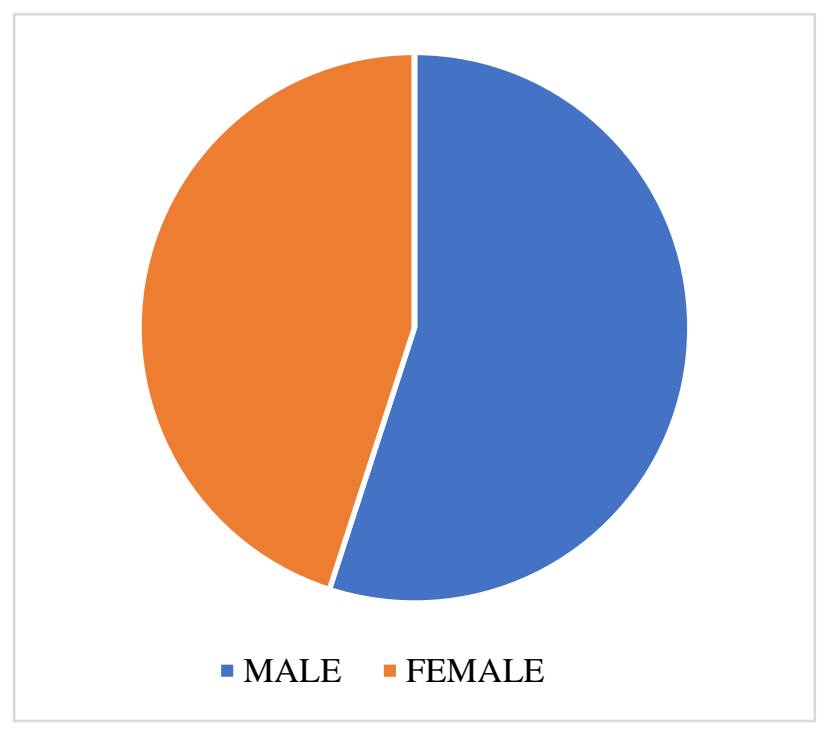

Figure 1: Gender wise distribution.

Lately, it was observed that the most preferred prescribing pattern for the mild depression, moderate depression and severe depression were antidepressants, antidepressants with benzodiazepenes and antidepressants with a combination of benzodiazepenes and antipsychiotics respectively (Table 3 ). 
Table 3: Prescribing pattern for depressive disorder.

\begin{tabular}{|lllll|}
\hline Depressive disorder & Patients (\%) & Antidepressants (\%) & Benzodiazepene (\%) & Antipsychiotic (\%) \\
\hline Mild & 20 & 90 & 5 & 1 \\
\hline Moderate & 48 & 96 & 55 & 10 \\
\hline Severe & 22 & 100 & 87 & 58
\end{tabular}

Drugs prescribed in accordance with the WHO list of medicines and NLEM, was found to be haloperidol $10 \%$ and escitalopram $85 \%$.

\section{DISCUSSION}

In the present study the escitalopram was the most commonly prescribed antidepressant drug followed by a combination drug 'citalinfote' and linotril etc. Grover et al in a multicentric study analyzed prescription data of 706 patients with depression in diverse teaching institution in public and private sectors and even privately run psychiatry clinics found that escitalopram was the most commonly antidepressant, comprising $40 \%$ of total prescription, followed by sertraline $(17.6 \%)$ and fluoxetine $(16.3 \%) .{ }^{7}$ Gang wang et al an 8 week open label, multicentric, single arm, prospective study conducted among 18-65 year olds at psychiatric outpatient unit found that escitalopram 10-20 mg treatment was efficacious in reducing depression, improving social function and quality of life. ${ }^{8}$

A study conducted by Carvalho et al revealed that safety, tolerability, adverse events and side effects were fewerin escitalopram (SSRI) than TCAs making it a widely used drug in treating major depressive disorder. ${ }^{9}$ Escitalopram and clonazepam was the most common combination used in polytherapy. Benzodiazepenes are co-prescribed for depressive disorder cases. The commonly prescribed benzodiazepenes were lorazepam and clonazepam which was also mentioned by Hussain et al. ${ }^{10}$

Lahon et al a retrospective drug utilization study on antidepressant in psychiatric unit found that antidepressant drug duloxetine (96) were mostly prescribed followed by escitalopram (43) but, the preferences for duloxetine over SSRIs as the first line drug in depressive disorder did not conform to the standard treatment guidelines (STG). Adequate dosing was seen for all antidepressants except duloxetine and mirtazapine where, underdosing was prevalent. ${ }^{11}$

A study conducted by Hussain et al reported that the patients on antidepressants were mostly in the age group between $20-40$ years acccounting to $51.25 \% .{ }^{10}$ Similarly, a retrospective observational study analyzed the case records of patients and revealed that antidepressants were distributed in the age group between 21-40 years as clarified by Lahon et al. ${ }^{11}$ Yerkade et al evaluated the prevalence of depressive disorder were mostly common in females $(170,56.6 \%)$ than males $(130,43.3 \%)$ and the maximum prescription rate was in the age group between
31-40 years. ${ }^{12}$ Similar to our study, the patients on antidepressants were mostly in the age group 31-40 years and antidepressants drugs were mostly prescribed in males $(30,60 \%)$, than females $(24,40 \%)$ because their social life is vary from other studies like most of the males were under daily wages workers and their economic status was unstable, which was further worsenedby COVID-19 pandemic.

In our study mostly propreitary named $(55 \%)$ medicines were prescribed compared to generic medicines. They were more expensive than generic drugs making it not affordable to most patients. Also, the growth in the number of fatal diseases and the cost of those medicines for such diseases were very high, use of generic drugs for treating other illness is strongly recommended. Mostly in our study antidepressants drugs were prescribed from NLEM which promotes to rational use of medicines considering the cost,safety and efficacy etc.

\section{Limitatons}

Our results should however be seen in the light of our small sample size, as compared to the studies with which they have been compared. This study was conducted in a controlled social environment and results may vary between hospitals. As with any drug utilization study quantification of the data on the comparative clinical effectiveness of the antidepressants were not possible. Moreover the sudden outburst of COVID-19 pandemic largely affected the patient followup for much more reliable outcomes.

\section{CONCLUSION}

Escitalopram was the most commonly prescribed drug for depressive disorder followed by lorazepam, linotril and haloperidol. Monotherapy was the most followed because of increased medication adherence, low ADRs, minimum cost and lesser drug interactions compared to other therapies.

\section{ACKNOWLEDGEMENTS}

Author would like to thanks to the mentors, head of the department of pharmacy and department of psychiatry for their encouragement, advise and full support to this study.

Funding: No funding sources

Conflict of interest: None declared

Ethical approval: The study was approved by the Institutional Ethics Committee 


\section{REFERENCES}

1. GBD 2017 Disease and Injury Incidence and Prevalence Collaborators. Global, regional, and national incidence, prevalence, and years lived with disability for 354 diseases and injuries for 195 countries and territories, 1990-2017: a systematic analysis for the Global Burden of Disease Study 2017. Lancet. 2018;92(10159):1789-858.

2. O'Donnell JM, Shelton RC. In Chapter 15 Drug Therapy of Depression and Anxiety Disorders. In Brunton BC,Chabner BA, Knollmann LL (Eds), Goodman and Gilman's The Pharmacological Basis of Therapeutics, $12^{\text {th }}$ ed. 2011. Available at: http://0www.accesspharmacy.com.innopac.wits.ac.za/conten t.aspx?aID=16663059. Accessed on 23, Jan 2020.

3. World Health Organisation. Introduction to drug utilisation research. Oslo: World Health Organisation, 2003. Available https://apps.who.int/iris/handle/10665/42627.

4. Sjöqvist F, Agenas IED. Drug utilization studies: implications for medical care. Proceedings from ANIS Symposium, SangaSæby, Sweden. Acta medica scandinavica. 1984;683:1-152.

5. Chennabathni CS, Brown DJ. Prescribing patterns in theSeychelles. Trop doctor. 1982;12:228-30.

6. Gonzalez JS, Shreck E, Batchelder A. Hamilton Rating Scale for Depression (HAM-D). In: Gellman MD, Turner JR. (eds) Encyclopedia of Behavioral Medicine. Springer, New York, NY. 2013.

7. Grover S, Avasth A, Kalita K, Dalal PK, Rao GP, Chadda RK et al. IPS multicentric study:
Antidepressant prescription patterns. Indian J Psychiatry. 2013;55(1):41-5.

8. Wang G, You X, Wang X, Xu X, Bai L, Xie J et al. Safety and effectiveness of escitalopram in an 8-week open study in Chinese patients with depression and anxiety. Neuropsychiatr Dis Treat. 2018;14:2087-97.

9. Carvalho AF, Sharma MS, Brunoni AR, Vieta E, Fava GA. The Safety, Tolerability and Risks Associated with the Use of Newer Generation Antidepressant Drugs: A Critical Review of the Literature. Psychother Psychosom. 2016;85(5):270-88.

10. Hussain A, Sekkizhar M, Asok Kumar M, Niramala P. An Observational Study on drug Utilization Pattern and Pharmacovigilance of Antidepressant Drugs. J Med Sci Clin Res. 2018;06(10):540-52.

11. Kingshuk Lahon, Harsha M. Shetty, Amith Paramel, Gyaneswar Sharma. A Retrospective Drug Utilization Study of Antidepressants in the Psychiatric Unit of a Tertiary Care Hospital. Journal of Clinical and Diagnostic Research. 2011 October, Vol-5(5): 10691075.

12. Yerkade V, Siddiqui RA. A drug utilization study of antidepressant drugs in a tertiary care hospital. Int $\mathbf{J}$ Basic Clin Pharmacol. 2017;6(6):1405.

Cite this article as: Thangamariyappan $\mathrm{C}$, Karnan D, Roshini G, Manna PK, Kumar A. A study on prescribing pattern and drug utilization among depressed patients in a tertiary care teaching hospital. Int J Basic Clin Pharmacol 2021;10:1282-5. 